\title{
Cuando Cristo "Se metió” a El Islote: culto evangélico, atmósfera ritual e interacciones sociales en un territorio insular del Caribe colombiano
}

\author{
ANDREa Leiva EsPitia \\ Doctorante en Antropología, École Pratique des Hautes Études, París \\ leiva.andrea@gmail.com
}

\begin{abstract}
Resumen
[ste artículo se basa en una etnografía del culto evangélico que se practica en El -Islote, un territorio del Caribe colombiano que se caracteriza por su alta densidad demográfica. Pretendo ilustrar una forma de religiosidad discontinua y fluctuante encarnada en la figura de dos pastores itinerantes, por medio de la descripción y el análisis de su incursión en la isla en el año 2010. Esta aproximación se presenta como una alternativa a la mayoría de los estudios sobre la presencia evangélica en Colombia, que se refieren a la existencia coherente y estable de las iglesias urbanas. Aquí me concentraré en la realización local del culto evangélico, entendido como un escenario provisto de dispositivos rituales como la música y las habilidades retóricas de los pastores, por cuyo medio se hacen explícitas situaciones de la vida social que en las interacciones cotidianas tienen generalmente una condición tácita.
\end{abstract}

PALABRAS ClAvE: culto evangélico, ritual, El Islote, Caribe, movilidad.

\section{When Christ "Got into" El Islote: Evangelic Cults, Ritualistic Atmosphere and Social Interactions in A Caribbean Island in Colombia}

\begin{abstract}
This article proposes an ethnographic approach to evangelic cults in the Islote, an insular area located in the Caribbean Coast of Colombia known for its high population density. The incursion of two foreigner pastors in 2010 is described and analysed in order to present a form of religiousness characterized by discontinuity and fluctuation. The article offers an alternative approach to most of the research done in the field of evangelic presence in Colombia, which usually describes urban churches as coherent and stable institutions. It focuses in the local performance of evangelic cult, understood as a setting of ritual devices, such as music and persuasive discourses that make explicit social features normally pushed into the background during interactions of everyday life.
\end{abstract}

KEYWORDS: evangelic cult, ritual, El Islote, Caribbean, mobility.

\section{Revista Colombiana de Antropología}

Volumen 48 (2), julio-diciembre 20I2, pp. 39-66 


\section{INTRODUCCIÓN}

$\left[\begin{array}{l}\text { n Colombia, las investigaciones }{ }^{1} \text { sobre el pentecostalismo se } \\ \text { dirigen principalmente al análisis histórico y sociológico de sus } \\ \text { procesos organizativos, políticos e institucionales. Esta corrien- }\end{array}\right.$ te religiosa es definida como "una modalidad de renovación del fervor religioso, inspirada en el pasaje bíblico del libro Hechos de

I Butler (1970, 1975), que trabajó sobre el impacto pentecostal en clases desfavorecidas; Brusco (1986, 1993), en el tema del género en comunidades evangélicas de Boyacá; Pereira Souza (1996, 1998), quien analiza con una perspectiva histórica y sociológica el pentecostalismo en Colombia desde 1960; Ríos (2002), quien estudió la relación entre los procesos identitarios y los religiosos en el Urabá antioqueño; Rondón (2007), con su análisis sobre la heterogeneidad pentecostal y la diversidad cultural; Sánchez (2004), que hizo un estudio etnográfico de las estrategias de trabajo, evangelización, crecimiento y aceptación del protestantismo en Quibdó (Chocó); y la compilación editada por Tejeiros (2010), que tiene un enfoque sociológico e histórico de las prácticas religiosas, el liderazgo y la participación política de diferentes iglesias pentecostales en Colombia.

2 La glosolalia es definida también como el don de lenguas, y se refiere a la aptitud de una persona para hablar "lenguas extrañas" sin conocerlas. Estas lenguas no tienen un significado particular (Garma 2008). El origen bíblico se encuentra en Hechos de los Apóstoles 2, y en la práctica, algunos autores ubican su origen en 1900 en Topesa (Kansas, Estados Unidos), cuando un alumno del pastor Charles Parham comenzó a "hablar en lenguas" después de que el primero le impuso las manos, con lo cual nació el movimiento pentecostal (Willaime y Baubérot 1990). los apóstoles (2:1-13) en el cual se narra lo que canónicamente se conoce como 'Pentecostés' o la venida del Espíritu Santo sobre los apóstoles [...]" (Ravagli 2010, 29), y se caracteriza por elementos como "la glosolalia ${ }^{2}$, los milagros y las sanidades, la adaptación de las ideas proféticas y el renovado impulso misionero" (Rondón 2007, 97).

Utilizo la categoría evangélico en el mismo sentido de Boyer (2008): como una noción local y no como una categoría de análisis. Con esta designo las expresiones carismáticas correspondientes al pentecostalismo, que ponen el acento en los dones del Espíritu Santo y en la inmediatez de las acciones de Dios, que permiten transformar a la persona en creyente (Baubérot y Willaime 1990). Por otro lado, utilizo la categoría pentecostalismo, en la introducción, para referirme a los estudios sobre esta corriente. No quiero desconocer el origen ni la importancia de las categorías en la discusión académica, pero considero pertinente remitirme a la realidad etnográfica de su utilización para dar cuenta de su reconfiguración local: en mi estadía, las personas reconocían el pentecostalismo, en contraste con el catolicismo, como "la religión evangélica" y/o "cristiana", y en algunos casos como "la religión de los pastores que vienen y van" o "la religión que anda por ahí". 
En su mayoría, los estudios se concentran en la descripción de iglesias urbanas ${ }^{3}$ que tienen presencia en diferentes ciudades de América Latina y Estados Unidos. A pesar de que en dichas descripciones se reconoce el carácter heterogéneo de las iglesias, la evangélica aparece como un tipo de religiosidad "compacta", de manera que la filiación institucional del "grupo de creyentes" por medio de un "sentimiento de pertenencia" y el papel de las iglesias como motores de "creación de lazos de identidad individual y colectiva" (Pereira 1996, 51) parecen evidentes. Así, a pesar de la riqueza de los distintos estudios, esa tendencia de análisis desdibuja la condición fragmentaria y discontinua del pentecostalismo, que tiene otras formas de expansión como la circulación de diferentes figuras individuales y la capacidad de adaptación local (Vilaça 2002), circunstancias en las que la afiliación a las iglesias no constituye un referente de la presencia religiosa.

Por otro lado, aunque algunos estudios afirman que la proliferación de las iglesias es una respuesta a la heterogeneidad económica, política, social y cultural del país (Pereira 1996) o a la existencia de múltiples "manifestaciones culturales en los sectores populares" (Rondón 2007, 106), en pocos casos ex-

3 Centro Mundial de Avivamiento y Centro Misionero Bethseda (Ríos 2010), Iglesia Pentecostal Unida de Colombia (Ravagli 2010) e Iglesia de Dios Ministerial de Jesucristo Internacional (Reyes 2010).

4 Algunas excepciones en los análisis de las prácticas religiosas en Colombia son los trabajos recientes de Ríos (2010), Ravagli (2010) y Reyes (2010), que dan cuenta de elementos esenciales (música, retórica) para comprender algunos aspectos de la práctica religiosa. No obstante, se limitan a describirlos en iglesias urbanas.

5 Con esto no niego la continuidad que esta corriente presenta en los elementos emotivos de la dimensión ritual y en el mensaje de "salvación" que transmite.

6 Este archipiélago se encuentra ubicado en el golfo de Morrosquillo, cerca de poblaciones costeras como Tolú, Coveñas y Rincón del Mar. Tiene nueve islas (Boquerón, Palma, Ceycén, Panda, Mangle, Isla Maravilla, El Islote, Múcura y Tintipán) y hace parte del departamento de Bolívar. ploran el contexto ritual ${ }^{4}$ o la variabilidad de los procesos de incursión pentecostal (y su recepción local) como características que posibilitan la expansión de esta corriente.

Ante este panorama, el presente artículo surge de la exploración etnográfica de un tipo de religiosidad local que da cuenta del carácter fluctuante de la territorialidad evangélica ${ }^{5}$. El marco territorial de este análisis es El Islote, un pequeño territorio insular (una hectárea de superficie) del Caribe colombiano que está ubicado en el archipiélago de San Bernardo ${ }^{6}$. Esta isla alberga aproximadamente a ochocientas personas, agrupadas en familias que viven de la pesca y el trabajo en el sector turístico. 
El Islote carece de una construcción destinada a la práctica religiosa. Históricamente, la religiosidad local ha estado representada por diferentes figuras y por la celebración de festividades dedicadas a los santos que son objeto de devoción, como la Virgen del Carmen y la Cruz de $\mathrm{Mayo}^{7}$. Antes de la incursión evangélica la presencia de representantes religiosos se redujo a la visita esporádica de algunos sacerdotes católicos que acudían anualmente a la isla para hacer rituales colectivos, en los que se celebraban de forma simultánea bautizos, matrimonios y primeras comuniones.

Pero desde finales del año 2009 El Islote ha recibido la visita de diferentes pastores evangélicos. El pionero fue un pastor originario de la República Dominicana llamado Juan Gabriel Peña, que llegó a la isla acompañado de otro pastor cartagenero conocido como el "profeta" Reinel ${ }^{8}$. Ellos permanecieron por

7 La Cruz de Mayo es un referente religioso y territorial en El Islote. Los primeros pobladores de esta isla, que llegaron aproximadamente a partir de la segunda mitad del siglo xIx, procedían de la isla de Barú (Cartagena) y llevaron consigo esta figura religiosa, considerada en ese entonces como un santo viviente. Por eso, el 3 de mayo se celebra el Día de la Cruz en El Islote.

8 En algunas guías y manuales de la literatura evangélica se distinguen diferentes tipos de líderes religiosos, como los apóstoles, los profetas, los evangelistas, los pastores y los maestros. Los profetas tienen varias características que los distinguen de los pastores, por ejemplo, predicen eventos, advierten sobre peligros y tienen una función de guías en la evangelización y en la expansión misionera (ver http: / / cayadopastoral. com/e/e 1-8.html). No obstante, como afirma Willaime (1986), los líderes pueden oscilar entre una forma de acción y otra o combinar varias formas de liderazgo.

En el caso que aquí analizamos, la adscripción a la categoría de profeta constituye una forma elegida por el mismo Reinel para distinguirse de otros personajes locales y extranjeros, que no está en relación estrecha con la función de este representante religioso. La diferencia en la jerarquía - que describiremos más adelante cuando hablemos de las fachadas personales de estos personajes - está definida por la personalidad de cada uno y no por la categoría religiosa.

9 Grupo pentecostal de gran alcance en todo el continente americano, creado en 1963. periodos de dos o tres semanas, y durante el año 2010 fueron en tres ocasiones a la isla. Además de circular constantemente en el archipiélago, estos pastores realizaron una serie de cultos públicos que ocuparon largas horas de las noches isleñas.

Después de esta primera incursión, la población de El Islote presenció la visita de otros pastores provenientes de ciudades del noroeste colombiano como Sucre, Montería y Cartagena, que no regresaron a la isla. Por último, en el año 2011, el presidente del Movimiento Misionero Mundial $^{9}$ en Colombia visitó una isla vecina y al divisar desde allí El Islote anunció la necesidad de incursionar en él. Por esto envió un primer grupo de tres pastores que se instalaron durante dos meses en la isla y luego fueron relevados por otro grupo. Gracias 
a esta dinámica el Movimiento logró insertarse permanentemente en la vida isleña.

Aunque este artículo se limita al análisis de las influencias del pastor Juan Gabriel y el profeta Reinel, en el repaso anterior se advierte la inestabilidad de la influencia evangélica, marcada en este caso por el vaivén de las figuras religiosas. Esta condición reclama un tipo de etnografía capaz de dar cuenta de la discontinuidad de los mecanismos de incursión. En este caso, la estadía prolongada en El Islote me permitió ser testigo del trayecto de los pastores y presenciar las formas locales de prolongación, disolución y recepción de la incursión evangélica. También pude acompañar a los pastores en sus recorridos por otras islas, y observar, de manera eventual, la asistencia de algunos habitantes de El Islote a otras iglesias en ciudades como Cartagena y Tolú.

En este artículo me ocuparé de una dimensión de esta etnografía: la observación y participación en los cultos de los pastores y la interacción cotidiana con ellos durante su estadía. Pero hay otro tipo de aproximación que resulta pertinente como marco de análisis, pues da cuenta de la movilidad del universo evangélico:

10 La antropóloga hizo su estudio en los estados de Amazonas, Pará, Amapa, Roraima, Tocantins, Rodonia y Acre.

11 Con esta categoría Boyer se refiere a los "pequeños predicadores" que dirigen su existencia a la propagación del mensaje religioso y no a la administración de una congregación. En este artículo, nos referiremos a esta misma figura con las palabras pastor y profeta, con las que la población identificó a estos personajes desde un principio. El pastor Juan Gabriel también se define como predicador o apóstol ante sus seguidores, y como evangelista en las redes sociales de Internet. El profeta, por su parte, conserva esta categoría en todo momento.

12 En este caso la autora se refiere a las poblaciones de la Amazonia que ella analizó. se encuentra plasmada en el trabajo de la antropóloga Veronique Boyer (2008), quien en su obra Expansion évangélique et migrations en Amazonie Brésilienne (Expansión evangélica y migraciones en la Amazonia brasileña) analiza los procesos de propagación del mensaje evangélico en caseríos de difícil acceso y en diversas zonas rurales ${ }^{10}$ con base en el seguimiento de los itinerarios y en las redes que se tejen en las trayectorias de los "evangelistas" 11.

Del estudio de Boyer es posible resaltar tres aspectos principales. En primer lugar se encuentra la figura del evangelista como motor de movilidad, ya que el hecho mismo de emprender una misión lo reviste de legitimidad como portador de la Palabra. Este aspecto no solo funciona como un factor de su reconocimiento como enviado de Dios y figura de la alteridad religiosa frente al catolicismo, sino que también favorece la presencia evangélica en las sociedades sometidas a una migración constante ${ }^{12}$. 
En segundo lugar, el contenido del mensaje bíblico que portan los evangelistas, basado en el tránsito de un pasado de sufrimiento y pobreza a un presente de salvación que lleva a los fieles a identificarse con la posibilidad de ser, ellos mismos, actualizadores de esta historia. Este es un proceso gradual, que resulta en la conversión de las personas y que Boyer identifica con

En nuestro caso, los isleños tienen como base territorial El Islote, pero son una población en constante circulación entre el archipiélago y distintas regiones costeras del continente colombiano, donde las personas encuentran puntos temporales de estadía (por razones médicas, laborales, educativas, familiares) para luego regresar a la isla.

13 Traducción libre del francés.

14 Gracias a la creación de puntos de anclaje (Boyer 2008) que promueven los mismos creyentes sobre la base de una informalidad. Según la misma autora, esta creación de puntos de práctica informal es anterior a la instalación de una iglesia por parte de los pastores.

15 Traducción libre del francés. la idea de un renacimiento. Este concepto también es mencionado por Sánchez como el "punto paradigmático" $(2005,103)$ de la conversión de los creyentes.

Por último, Boyer señala las diferencias entre la territorialidad evangélica y la católica. Esta última "reposa sobre el sistema de parroquias y admite particularismos como el vínculo con un santo patrón, pero supone la participación de todas las personas en el culto [...]"13 $(2008,124)$.

En el caso evangélico se trata de una territorialidad transitoria que depende "menos de la planificación de las Iglesias y más del esfuerzo del creyente" ${ }^{14}$ (122). Con esto la autora se refiere al papel de los adeptos en la formación de puntos de práctica informal que abren paso a la posterior fundación de iglesias por parte de los evangelistas. En el caso de El Islote no es común encontrar - por lo menos no lo fue durante mi estadía- esta autogestión de congregaciones en torno a la oración por parte de la población. Pero la condición transitoria de la territorialidad evangélica se expresa en la prolongación del mensaje bíblico con la proyección de material audiovisual que entra a la isla gracias a comerciantes itinerantes provenientes de zonas costeras, o por medio de emisiones de radio y de la visita constante de nuevos pastores. En este escenario, el culto evangélico se puede entender como uno de los puntos de anclaje de esta territorialidad.

Aunque la dimensión ritual no es analizada por la autora, Boyer sí da cuenta de una paradoja: a pesar de su fragmentación, las descripciones que versan sobre el universo religioso evangélico muestran un léxico paralelo que "da la impresión de una uniformidad de la experiencia religiosa y de la estructura ritual, sin importar la sociedad considerada" $(2008,192)^{15}$. Con 
esto se refiere a la emoción intensa, la música, el movimiento del cuerpo, la experiencia extática de los cultos y la idea del renacimiento ${ }^{16}$. Así, podemos preguntarnos: ¿cómo se presentan estas continuidades y discontinuidades en el culto evangélico que analizamos aquí?, ¿cuáles son las posibles funciones rituales de este evento en un territorio con las particularidades de El Islote?, ¿qué pasa cuando este proceso surge de la condición transitoria de los pastores?

A partir de estas inquietudes, las páginas que siguen describen y analizan la incursión evangélica -y su dimensión ritualen El Islote, recurriendo a la perspectiva dramatúrgica ${ }^{17}$ de Goffman (1973), pues esta per-

16 Boyer menciona, por ejemplo, el estudio de Doublemortier (1997), que analizó un grupo pentecostal en París, o del teólogo estadounidense Harvey Cox (1995). También podemos encontrar continuidades, en el contexto nacional, en la etnografía de Sánchez (2005) en Quibdó (Chocó) y en el análisis de Ríos (2010) sobre los discursos que se practican en dos iglesias neopentecostales de Bogotá.

17 Goffman describe la interacción social a partir de la metáfora teatral, de modo que las interacciones sociales constituyen performances del individuo (actor) frente a una audiencia.

18 Estas referencias son esporádicas, y aunque en ciertos grupos de jóvenes existe una clara demarcación de la territorialidad con respecto al "barrio" de pertenencia, el hecho de pertenecer al barrio de arriba es una categorización de carácter circunstancial y no implica que El Islote sea una sociedad de opuestos binarios. mite comprender las formas de participación, la disposición del escenario ritual y el despliegue de habilidades retóricas - tanto por parte de los pastores como del público- como motores de esta experiencia religiosa.

\section{LA LLEGADA DE LOS "ENVIADOS DE DIOS": LA CONDICIÓN DUAL DE SU PRESENCIA}

principios del año 2010 (en su segunda visita), el pastor Juan
Gabriel llegó a El Islote cuando los pescadores todavía no ha-
bían regresado de sus faenas. Muchas mujeres se encontraban en sus casas protegiéndose del sol que calentaba directamente el suelo de la plaza de la Cruz, ubicada en un barrio que los habitantes llaman Pueblito. Este sector está separado del resto de la isla por la calle de la Cruz, que divide la isla en dos zonas: el barrio de arriba y el barrio de abajo ${ }^{18}$. La frontera entre la calle de la Cruz y la plaza del mismo nombre alberga la representación en cemento de la Cruz de Mayo, patrona de la isla.

Más tarde, desembarcó en la isla el profeta Reinel, custodiado por un grupo de niños que lo saludaban, entonando al mismo tiempo sus canciones. Al llegar la noche, un grupo de amigos y 
ayudantes isleños ${ }^{19}$ del pastor comenzaron a disponer los materiales para el culto: una tarima improvisada hecha en madera y fabricada por voluntarios, que ubicaron en un extremo de la plaza; los bafles del sonido, situados en un costado de la tarima; y un bombillo que expedía un tenue hilo de luz que apenas alumbraba el escenario. La electricidad era generada por una pequeña planta eléctrica, propiedad de uno de los comerciantes de la isla, quien, junto con su familia, eran los anfitriones más fieles del pastor. Aunque el espacio destinado a los asistentes era la plaza, otros lugares eran propicios para tener una panorámica del culto: la escuela (que ofrece una perspectiva de casi toda la isla) y las casas que rodean la plaza.

Durante el día, el pastor Juan Gabriel no efectuó ninguna actividad que congregara a las personas en torno a su labor religiosa. Más bien, se desplazó por toda la isla, saludando e intercambiando bromas y experiencias. Su acento dominicano resultaba

19 Forma con la cual se autodefinen los habitantes de El Islote para diferenciarse de sus vecinos de la isla de Múcura, que son llamados mucureros. Esta categoría también funciona algunas veces como marcador identitario, en los encuentros de los isleños con personas de poblaciones costeras cercanas.

20 Como " ¡Cristo te ama, hermano!", "idetente, Satanás!", "igloria a Dios!". cómico para los isleños, quienes adoptaron algunas de sus frases como parte de sus expresiones cotidianas, y así aún se pueden escuchar en las conversaciones informales. La presencia del pastor durante el día, así como su manera de vestir, sus gestos y su lenguaje verbal, no estaban revestidos de su condición religiosa. Por el contrario, el profeta Reinel era más serio en su aspecto y su lenguaje siempre estaba signado por consignas evangélicas ${ }^{20}$.

$\mathrm{Al}$ caer la noche la gente se preparó para el culto y cambió su vestuario habitual por uno más formal, pero no necesariamente más cubierto, pues el pastor Juan Gabriel no establecía límites en este aspecto (como si sucedió con un grupo de pastores que visitaron la isla meses después). Por su parte, este último y el profeta sí cambiaban completamente su vestido por uno más cubierto y formal, y así mismo transformaban su actitud, pues para el momento del culto el pastor asumía una posición autoritaria que contrastaba con sus interacciones diurnas.

Este cambio de posiciones de los pastores ilustra las diferentes facetas de la actuación o performance, que Goffman (1973) define como la actividad ejecutada por un actor ante un grupo de personas que se encuentran sometidas a su influencia durante 
un tiempo determinado. Uno de los elementos de esta actuación es la fachada personal de los actores, término que designa los elementos vinculados con la persona del actor y que funcionan como signos distintivos ${ }^{21}$. En el caso del pastor Juan Gabriel, este aspecto tenía diferentes tipos de efectividad social entre la gente de la isla: por un lado, el hecho de presentarse como isleño, caribeño y proveniente de un barrio popular $^{22}$ le permitió establecer una cierta familiaridad cultural con las personas; sin embargo, el pastor Juan Gabriel siempre
21 Como la vestimenta, el sexo, la edad, las características raciales, la actitud y la forma de hablar.

22 El pastor reivindicaba constantemente su sector de origen: Barrio Blanco, en la provincia de San Pedro de Macorís, en el sureste de la República Dominicana.

23 Oriana Alonso (2010) nos ofrece una aproximación novedosa a las funciones sociales del humor, por medio de una etnografía de El Islote, en su tesis de grado titulada "Una gran familia: humor e identidad en El Islote de San Bernardo, Cartagena-Bolívar".

Además de frases y chistes, el pastor incrementó la distribución y conocimiento de varias películas dominicanas, como Perico ripiao y El santi panki, entre otras que ilustran sucesos marcados por la "viveza" de los autores, la posibilidad de engañar a las autoridades y su relación con los turistas. A El Islote entran por vía de comerciantes itinerantes que vienen de zonas cercanas. figuraba como un isleño extranjero, y el signo distintivo de esta condición era su acento dominicano.

Así, durante el día, el aspecto más destacado de la interacción cotidiana entre el pastor y los isleños era el humor ${ }^{23}$, acompañado de una vestimenta informal que lo acercaba a los jóvenes y una presencia que muchas mujeres consideraban atractiva. Por su parte, el profeta Reinel combinaba una fachada personal doble: la formalidad en la vestimenta y en el lenguaje religioso contrastaba con la espontaneidad de su actuación ritual, caracterizada por sus habilidades histriónicas como cantante y bailarín en los momentos del culto. Esta última postura le permitió adquirir una gran popularidad entre la gente, especialmente entre los niños.

La doble condición en la actuación permitía una dinámica de complementariedad entre ellos, pues en la interacción por fuera del culto el profeta asumía una posición de sumisión frente al pastor. Esta se expresaba también por medio del humor, por ejemplo en las bromas constantes que el pastor le hacía al profeta sobre su forma de bailar o su apariencia cómica, chanzas que este último generalmente respondía (o eludía) con consignas religiosas como: “iGloria a Dios!”, “iamén!” “ialeluya!”. Con estas respuestas el profeta Reinel asumía una postura pasiva ante el despliegue de habilidades humorísticas del pastor. En el culto, la relación de sumisión proseguía, pero ahora en relación con el estatus religioso del pastor, pues la apariencia de autoridad de 
este último contrastaba con la figura divertida que representaba el profeta, que sobresalía en ciertos momentos del culto.

\section{LAS DISTINTAS ESCENAS DEL CULTO: EL DESPLIEGUE RITUAL DE LAS TENSIONES COTIDIANAS}

\section{Las mujeres y los niños: los primeros asistentes}

a luz del día en El Islote es valorada y aprovechada al máximo, sobre todo por las mujeres, que al caer la tarde, cuando ha -mermado el tiempo de calor intenso que los isleños denominan fogaje ${ }^{24}$, encienden sus fogones de leña o estufas de gas para preparar la cena, después de que los hombres han provisto el pescado o la $\operatorname{lig}^{25} \mathrm{y}$ el dinero para la comida. Aunque actualmente existe una planta eléctrica que funciona entre las siete y las once de la noche, para la llegada de los pastores esta se encontraba dañada. Así, la asistencia de las mujeres al culto de Juan Gabriel y el profeta Reinel estaba supeditada a la aceleración de sus labores domésticas (preparación de la cena, baño de los niños, etc.).

Al caer la noche, los primeros asistentes eran en su mayoría mujeres y niños, más tarde, comenzaban a aparecer los hombres

24 Calor intenso que dura desde las diez de la mañana hasta las tres de la tarde aproximadamente.

25 Esta noción es extendida en la costa norte de Colombia y tiene diversos significados. En este contexto específico designa la porción de proteína que complementa el plato de comida, generalmente compuesto por arroz, y el tipo de carne más asequible - en este caso predominaba el pescado-. Carlos Durán (2007) nos ofrece un interesante análisis de esta noción y su papel en el intercambio económico en las islas del Rosario.

26 Boyer señala el trabajo de Roberto Da Matta (1987), quien se ha ocupado de las categorías sociológicas de la calle y la casa. Al respecto podemos mencionar también la referencia de Losonczy (2007, 126) cuando nos habla de la calle como el espacio de la sociabilidad masculina entre los hombres negros del Chocó. mayores y jóvenes. Este papel predominante de las mujeres es mencionado por Boyer (2008) en el caso de la Amazonia brasileña. La autora muestra la forma en que el discurso evangélico contribuye a la subversión de las relaciones familiares sin necesidad de romper con la lógica de los papeles en la relación conyugal, en la cual la normatividad implícita es la subordinación económica y doméstica de la mujer. El hombre encuentra más espacio en la calle ${ }^{26}$, donde tiene acceso a la fiesta y la bebida. Así, 
la práctica evangélica le permite a la mujer servirse del poder divino como argumento para insistir en la conversión del esposo, sin necesidad de poner en tela de juicio el poder masculino en diferentes ámbitos (Boyer 2008) ${ }^{27}$. En El Islote esta situación era perceptible en el afán femenino por ocupar el espacio ritual. Por su parte, los pastores y sus ayudantes se ocupaban de la organización del escenario. Esta actividad implicaba también la demarcación de fronteras entre el espacio principal y el espacio destinado al público.

\begin{abstract}
27 Con esto no quiero expresar que la mujer en El Islote sea un ser pasivo y oprimido frente al hombre. Tampoco que su participación en el ámbito evangélico sea el motor de un movimiento estratégico para reversar el machismo, según una explicación de corte feminista como la de Brusco (1995). La idea es enmarcar, de manera muy general, la tendencia isleña de los roles sexuales: a la mujer le corresponde el espacio del hogar; está supeditada a la capacidad del hombre como proveedor para poder gestionar sus labores; y sus actividades económicas son, en la mayor parte de casos, un complemento de las del hombre (Boyer 2008). Este último le da preponderancia a la calle (si bien esta categoría en El Islote no tiene fronteras estables), y su papel como proveedor le otorga un lugar de poder en muchas decisiones de la vida doméstica; no obstante, este dominio tiene grados distintos en cada familia.
\end{abstract}

\section{Organización del espacio ritual: entre el escenario y los bastidores}

A

ntes de comenzar el culto la mayor parte de los asistentes traía una silla desde su casa para ubicarse en la plaza central, y los Imás afortunados obtenían las primeras filas. Otras personas escogían lugares alternos a la plaza, como las plantas altas de la escuela, para tener una perspectiva general de la escena ritual. Algunos preferían ocupar lugares menos evidentes y más lejanos, pues expresaban una cierta timidez ante la posibilidad de ser escogidos por el pastor para pasar adelante y ser bendecidos. Mientras los asistentes se ubicaban, los isleños más conocedores de los asuntos técnicos (como el manejo de los equipos musicales y de la electricidad) probaban los equipos en un costado de la tarima. Los pastores participaban generalmente de la preparación del escenario en los momentos previos al culto, indicándoles a los ayudantes qué canciones serían utilizadas en cada momento.

Cuando todo estaba dispuesto, el pastor organizaba espacialmente la escena del culto y les pedía a los niños que se pararan al frente de la tarima y a los adultos que se ubicaran detrás de los niños, para que estos pudieran disfrutar del momento de la alabanza. Esta preocupación del pastor por disponer los espacios de 
participación del público evoca la disposición de los dos espacios denominados por Goffman (1973) los bastidores (backstage) y el escenario (frontstage). Según este autor, en el escenario el actor puede disimular comportamientos que surgen tras los bastidores.

En el culto se puede identificar como escenario la tarima que construyeron voluntarios de la isla, pues era el lugar desde el cual se oficiaba. El papel de los bastidores lo cumplían los espacios que rodeaban la tarima, donde los pastores interactuaban entre ellos y también con los ayudantes. Por último, las casas que rodean la plaza de la Cruz funcionaban también como bastidores secundarios con respecto a los lugares más próximos a la tarima. El pastor se movilizaba entre estos bastidores para bendecir a las personas que requerían de su atención en los momentos posteriores al culto.

Aunque había gente que circulaba constantemente alrededor de la tarima y otros que seguían el culto desde su parte posterior, el pastor estableció desde el principio una frontera imaginaria, cuando les pedía a las personas apartarse de la tarima. Los oficiantes descendían constantemente al espacio del público y les preguntaban a los asistentes más cercanos el nombre de algunas personas a quienes desearan bendecir. Así mismo, el pastor le daba órdenes al profeta para que sostuviera el micrófono o para que se encargara de la bendición de alguna persona, les ordenaba a ciertas personas subir a la tarima y les pedía a los asistentes musicales cambiar las canciones. Aunque estas acciones eran visibles para algunas personas, el pastor les otorgaba un carácter oculto, pues parte de la comunicación que se llevaba a cabo en los bastidores evocaba una gestualidad del secreto que se expresaba cuando el pastor les decía cosas al oído a sus ayudantes, al profeta y a otros participantes cercanos.

Así mismo, en los lugares que circundaban la plaza, como la escuela y las casas, era posible distinguir otros grados de interacción del público: allí se ubicaban personas que aspiraban a ser espectadores y no participantes activos, pues intentaban ocultarse de la vista del pastor. No obstante, era difícil escapar de su perspectiva, pues en los momentos en los que él no era protagonista — como la alabanza - el pastor buscaba tras bastidores a los asistentes más esquivos. 


\section{La alabanza como marcador de estilo ritual y de reputación social}

r l culto inicia con el saludo del profeta Reinel, con la consigna: “¿Quién vive?”, a la que el público responde al unísono: “iCristo!”. Este momento es breve, y posteriormente el profeta les pide a los encargados de la música activar las pistas de sus canciones para darle paso a la alabanza. El profeta es reconocido como un cantante de champeta ${ }^{28}$ y reggaetón ${ }^{29}$ que declara haber sido llamado por Cristo para salir del mundo de drogas en el cual se encontraba sumergido. Decidió entonces utilizar su talento como cantante de champeta (que antes cantaba en un contexto "mundano" ${ }^{30}$ ) para adorar a Cristo. Los participantes más activos en este momento son los niños, quienes, ubicados inmediatamente al frente de la tarima, entonan con euforia sus canciones. La influencia de estas melodías no se limita al culto, pues se prolonga a varios espacios cotidianos que no tienen carácter religioso ni colectivo.

Ravagli afirma que para las iglesias pentecostales la alabanza "constituye un medio fundamental de su construcción identitaria

28 Música de origen africano inspirada especialmente en ritmos congoleses. El contexło caribeño colombiano adquirió matices que la dividen en dos categorías: la champeta africana y una champeta adaptada fonética e instrumentalmente, llamada champeta criolla. Para efectos religiosos, el profeta solo se basaba en los ritmos básicos de las pistas de la champeta, y construía letras de alabanza.

29 Música caribeña que combina ritmos como el hip-hop y el ragga.

30 Para los evangélicos el mundo representa el espacio externo a Cristo, es decir a la moral cristiana que excluye de su esfera aspectos como la bebida y la fiesta (Bauberot y Willaime 1990). y de la cohesión institucional" $(2010,155)$. El autor se refiere a una iglesia urbana de gran alcance latinoamericano, que funciona en espacios cerrados y que reúne a personas que asisten con un propósito establecido. Pero vale la pena preguntarse sobre la manera en que casos locales, que resultan de la trayectoria de los pastores y se constituyen en ofertas inesperadas para la gente, replantean la relación (que el autor nos presenta como directamente proporcional) entre la alabanza y el "sentimiento de pertenencia y vínculo comunitario" (155). Pues, por un lado, el estilo del culto determina claramente la intensidad de la participación, y por el otro, una persona que se declara católica y adora a diversos santos puede cantar y repetir estas canciones argumentando que ante todo le interesa alabar a Dios, de manera independiente de la doctrina. 
En este caso, podemos decir que la alabanza funciona como una marca del estilo o de las costumbres (Boyer, 2008) de cada representante evangélico, y no como un momento de activación de signos de unión y cohesión en una comunidad evangélica. En el caso de El Islote, este momento está marcado por la puesta en escena de las habilidades para el canto y el baile, que incluso se expresan individualmente, cuando el profeta, considerado como un excelente bailarín, llama a los mejores bailarines de la isla para que suban a la tarima, a la manera de un concurso animado por el público. Las competencias para el baile son un elemento

31 Según Peter Wilson, la reputación es "un estándar de valores, de las medidas de valor de una persona, derivado de su conducta con la otra gente" (2006, 257).

32 En Colombia, es característica de la narración de los partidos de fútbol la elevada velocidad del habla, que permite narrar la experiencia al mismo tiempo que sucede; así, podemos hacer un paralelo entre esta experiencia y la narración del profeta Reinel.

presente en varios contextos de la vida social isleña y constituyen habilidades que hacen parte de la constelación de elementos relacionados con la reputación social $^{31}$ (Wilson 2004, 180).

Así, la alabanza puede entenderse también como un espacio propicio para demostrar estas competencias con el acompañamiento musical de ritmos provenientes del contexto "mundano", pero que evocan temas religiosos, como el poder de Dios sobre los demonios y diferentes pasajes de la Biblia. Así mismo, el "concierto" creado por el profeta durante la alabanza está desprovisto de tensiones y lleno de muestras de alegría, a la manera de un "bloque" musical, cuya figura central es el profeta. Luego ocurre un cambio radical en la atmósfera, que anuncia la introducción de la Palabra.

\section{La Palabra: la realización dramática como motor de la unción}

l pastor Juan Gabriel no baila ni canta, tampoco participa en - la alabanza; en este momento del culto él solamente es un Lobservador. Su participación comienza cuando su compañero Reinel declara el fin de la alabanza y el comienzo de la Palabra. Entonces se apaga la música y el profeta emite un discurso a la velocidad de un narrador de fútbol colombiano ${ }^{32}$, en el que evoca sensaciones como la de una brisa fresca que entra a la isla. Este tránsito entre la alabanza y la Palabra hace referencia a una 
temporalidad instantánea, que nos dirige a la sensación de que algo está pasando en el momento mismo de la narración, como lo ilustra el siguiente aparte: "iSe siente una brisa fresca! iEs la entrada del Espíritu Santo! iLlegó!

33 En algunos casos comienza a hablar en lenguas (glosolalia) en medio de esta narración. iSe metió! iSe metió Cristo en El Islote! iFuera la brujería, fuera la idolatría! iSopla, sopla, Espíritu Santo, en El Islote! ${ }^{33}$.

Ahora bien, los narradores de fútbol describen cada movimiento del partido en el instante mismo de su desarrollo; claro está, esos momentos son visibles para los espectadores. En el caso del profeta Reinel, la narración se basa en sensaciones como las destacadas en el pasaje que acabamos de citar, y no en los movimientos visibles del fútbol. Pero en los dos casos existe el común denominador de la superposición entre la enunciación y el evento narrado.

Aquí podemos rescatar algunos elementos de lo que Goffman denomina la realización dramática. Se trata de la necesidad de comunicar en el momento mismo de la interacción las intenciones del actor, para conseguir un efecto sobre el público. El autor dice que además de comunicar (corporal o verbalmente) sus intenciones, el actor debe expresarlas "en una fracción de segundo" $(1973,36)$. Según la misma idea, en este proceso debe abandonar cualquier espacio de reflexión sobre la certitud de sus acciones. En el ritual que aquí se analiza, esta circunstancia tiene dos efectos: por un lado, le otorga un carácter de legitimidad a su actuación; por otro, la hace más efectiva que el ritual católico, pues en su narración el profeta apela a una temporalidad que combina la inmediatez del milagro y la de la transformación de la experiencia individual y colectiva. Esta temporalidad contrasta con la duración prolongada de las promesas de los creyentes a los santos católicos.

Así, la intención de la narración del profeta Reinel parece ser persuadir al público de la certitud de las distintas sensaciones (una brisa fresca) que evocan la entrada del Espíritu Santo. Esta construcción de sensaciones por medio de las palabras del pastor y del profeta no solo es perceptible a través de esta narración, también lo es en otros momentos en los que el pastor Juan Gabriel declara la presencia de demonios y los señala con el dedo para que "la gente los pueda ver", y emite frases como "iyo sé que ustedes están viendo lo que yo estoy viendo!”. 
A propósito de este proceso, es pertinente resaltar el análisis discursivo que hace Ríos (2010) acerca de la construcción retórica del milagro en el caso de una iglesia de gran alcance a nivel latinoamericano. La autora nos muestra cómo los dispositivos retóricos (énfasis, habilidades) utilizados por los pastores en su interacción con el público transforman la experiencia de sanación. Ríos describe el caso del testimonio público y muestra la manera en que la interacción se convierte en el motor de reconocimiento del éxito del milagro. Así, la narración rápida que hace el profeta Reinel se puede sumar a la lista de dispositivos retóricos que, marcados por la velocidad y la temporalidad que indica su contenido (como en la frase "ise metió, se metió Cristo en El Islote!”), contribuyen a la construcción de la sensación de una presencia divina.

Las respuestas del público a esta narración rápida son disímiles: unos lloran, otros cierran los ojos y oran, otros caen al suelo, y es entonces cuando el pastor Juan Gabriel entra con la Palabra. En ese momento el pastor les ordena a los encargados del sonido poner una balada cristiana, y a los niños que pasen detrás de los adultos para "evitar la entrada del demonio en su cuerpo". El pastor introduce la Palabra con un tono en algunos casos amenazante, desprovisto de la familiaridad que lo caracteriza durante el día, con frases como "ihay gente que anda diciendo que yo soy brujo!", y posteriormente amenaza con no volver a la isla si continúan los rumores. Hay personas que siempre lideran las respuestas a estas amenazas, diciéndole frases como "ino, pastor, nosotros lo queremos mucho!”.

Esta postura "ceremonial” 34 (Goffman 1973) del pastor contrasta con la familiaridad diurna de sus interacciones y tiene elementos que están condicio-

34 Goffman hace referencia a los roles estrictamente ceremoniales $(1973,101)$ para designar aquellos actos en los que las personas se interesan casi exclusivamente por la apariencia que presentan. No obstante, en el culto, el pastor Juan Gabriel le otorga tanta importancia al despliegue dramático como a la apariencia pasiva de su figura religiosa. nados a una preparación previa. Por ejemplo, él se preocupa por averiguar a lo largo del día (antes del culto) las impresiones que causa entre la gente, haciendo preguntas casuales sobre las sensaciones que produce cuando comienza a hablar con un tono fuerte.

El momento de la Palabra no está provisto de un orden establecido, pues en otros casos el pastor puede comenzar llamando 
a determinada persona para ser bendecida. Al mismo tiempo, organiza la escena del culto llamando a sus ayudantes para que se paren detrás de las personas con el fin de evitar que la gente que caiga al suelo se golpee la cabeza. Estos corren entre la gente y se paran detrás de aquellas personas que el pastor está bendiciendo, mientras que otras permanecen de pie, orando con las manos elevadas y los ojos cerrados. No todas las personas caen, pero el hecho de que ocurran múltiples caídas al tiempo es un dispositivo de legitimación del pastor, que en El Islote las personas designan con la palabra unción.

Podemos interpretar la unción del pastor como una de las "unidades de medida" de su éxito. Esta juega un papel muy relevante en la preferencia de un pastor sobre otros y se relaciona con las habilidades retóricas que acabamos de describir. La unción puede interpretarse entonces como una articulación entre esos discursos persuasivos y su efectividad visible, que se expresa en la manifestación corporal de la bendición. Como señalamos arriba, una de las expresiones de la unción es la caída en masa de la gente después de que el pastor ha emitido frases como "isopla sobre El Islote, Espíritu Santo!”. Estas frases son seguidas por varios soplos fuertes que toda la gente puede escuchar: a medida que el pastor sopla, más cuerpos caen, y este momento inaugura una etapa de escenas simultáneas que el pastor llama las liberaciones, que es el nombre que en el lenguaje pentecostal se les da a los exorcismos ${ }^{35}$. La liberación constituye una de las formas de sanación (Garma 35 Según Garma (2004), la designación de liberación se utiliza para evitar las connotaciones negativas y sensacionalistas de la palabra exorcismo en los contextos externos al pentecostal. Sin embargo, la palabra liberación parece tener un significado más amplio en el contexto evangélico. Es posible encontrar algunas referencias a la liberación como un ministerio (Garma 2004), un evangelio (Salas 1998) o un don basado en el libro Hechos de los Apóstoles 2.

36 En El Islote esta posesión se le atribuía generalmente a un demonio de brujería "puesto" (Salas 1998) por otra persona, y se materializaba por varias vías: un veneno o bebedizo aplicado en la sopa de la persona embrujada, la utilización de una fotografía para afectar el cuerpo de la persona con enfermedades, el enterramiento en el cementerio de vestimenta robada para que su dueño se debilite poco a poco, etc. 2004) y supone la posesión del cuerpo de la persona por parte de un demonio ${ }^{36}$ que debe ser expulsado para que la persona sea liberada. 


\title{
Las liberaciones: el trance, las posesiones con manifestación y las posesiones pasivas
}

\begin{abstract}
l contrario de la alabanza, que es un momento de interacciones más o menos continuas, los lapsos destinados a la Palabra y las liberaciones tienen en común la confusión y la discontinuidad de los eventos. Esta discontinuidad se percibe en diversos fenómenos, como los cambios en el volumen de la música, que son ordenados por el pastor, los recorridos de los ayudantes que sostienen los cuerpos, las oraciones inconexas de las personas que no caen y que permanecen con los ojos cerrados, y los desplazamientos constantes del profeta y del pastor, que van y vienen entre la gente y la tarima intercambiándose los micrófonos para explicar los sucesos o para seguir expresando consignas con las cuales les ordenan a los demonios salir de los cuerpos.
\end{abstract}

Tales consignas u órdenes pueden tener dos efectos: 1) que la persona que cae al suelo se quede quieta con los ojos cerrados, o 2) que una vez en el suelo comience a convulsionar y a vomitar y

37 Ver, por ejemplo, Mateo 9:32-33 y 17:14, Lucas 4:33-36, Marcos 5:1-20 y Hechos 16:16-18. Estos pasajes hablan de diferentes formas en las que Jesús reconoció la presencia de espíritus demoníacos en personas que presentaban síntomas como mudez, ceguera, epilepsia y/o problemas mentales, entre otras manifestaciones. En estos pasajes se resalta la capacidad de Jesús de liberar a las personas, por medio de órdenes y amenazas dirigidas a los espíritus demoníacos, de la presencia de estos espíritus malignos. experimente cambios en su voz. En algunos casos, en el momento de ser bendecida la persona se niega a caer y enfrenta al pastor con su cuerpo. Estas reacciones, que evidencian diferentes tipos de posesiones demoníacas, asociadas con diversos pasajes de la Biblia $^{37}$, son similares a las que relata el siguiente párrafo, tomado del trabajo de Salas (1998) acerca de la iglesia Dios es Amor, en Venezuela:

[...] los poseídos atraviesan situaciones difíciles, cuando los demonios tercos y resistentes se aferran al cuerpo y se niegan a desalojarlo. En esta lucha tenaz dejan oír su voz — débil—a través de la garganta del poseído alegando ser dueños de este cuerpo, con un rostro también desfigurado con rictus deformantes y ojos desorbitados, que dramatizan la situación del terror, el cuerpo del poseído arrodillado o acostado en el suelo entabla una lucha feroz contra el mal. $(1998,27)$

Es posible analizar estas expresiones como estados de trance vinculados con la posesión. Tanto el primer como el segundo 
concepto han sido discutidos en la literatura antropológica, principalmente en los análisis de los cultos de posesión de sociedades africanas (De Heusch 2006; Rouget 1990) ${ }^{38}$ y afroamericanas (Bastide 1972), desde perspectivas distintas ${ }^{39}$. De manera general, estos análisis entienden la posesión como la entrada de un espíritu en el cuerpo de una persona y como una de las formas en que se presenta el trance. Por su parte, según afirma Rouget, el trance es "un estado pasajero de conciencia, o como su nombre lo indica, transitorio", que tiene elementos como el movimiento, el ruido, la estimulación sensorial y la amnesia $(1990,56)$. Para De Heusch, en algunos tipos de posesión ${ }^{40}$ el trance es "la manifestación de un espíritu patógeno que toma posesión del cuerpo imprimiéndole un comportamiento anormal" $(2006,55)$. El trance no se puede entender por fuera de un contexto ceremonial establecido (Bastide 1972), donde hay un oficiante que lo induce (De Heusch 2006).

Así las cosas, es posible decir que en el culto evangélico ocurren posesiones que se manifiestan, en algunos casos, en el trance que corresponde a la tipología señalada por Rouget (1990). En el culto local que aquí se describe estas reacciones son definidas por el pastor como manifestaciones, es decir, ocasiones en que el demonio usa el cuerpo de la persona para comunicarse. Mientras tanto, el estado de quietud, similar al sueño, en el que cae la mayoría de las personas, no corresponde a la tipología del trance que señalamos arriba, pero es definido por el pastor como una posesión (sin manifestación), que es posible llamar posesión pasiva, en la cual el demonio que habita el cuerpo de la persona no lo usa para comunicarse ${ }^{41}$. En los dos casos juega un papel esencial el pastor como garante de facultades especiales para detectar a los demonios, sin necesidad de que se manifiesten, y 
para enfrentarse a los demonios manifiestos con el fin de realizar las liberaciones de los cuerpos de las personas poseídas.

En el caso de la posesión pasiva, para liberar a la persona del espíritu invasor el pastor le impone las manos en la cabeza y emite oraciones que anuncian "la salida de todo demonio de su cuerpo", luego la persona cae al suelo y se queda inmóvil y con los ojos cerrados hasta que el pastor anuncia el fin de las liberaciones. En el caso de la manifestación el pastor también impone las manos sobre la cabeza de la persona, que convulsiona o se levanta del suelo y comienza a forcejear para no dejarse bendecir. En ocasiones le dice oraciones al oído, con frases como "iEspíritu santo, declara la salida del demonio de este cuerpo!”, pero cuando el demonio se manifiesta oralmente, es decir, cuando la persona comienza a hablar de manera inconexa y con un tono de voz no habitual, el pastor llama a este un "demonio rebelde" y entabla una lucha directa con el cuerpo de la persona, ya sea sosteniéndola con fuerza en el suelo o agarrándola con las manos y mirándola fijamente a los ojos. Por ejemplo, durante uno de los cultos, el pastor identificó un demonio rebelde en una mujer que cambiaba la voz; ella se paró y él le dijo: "iDemonio, vete de ese cuerpo ya!”, y ella le daba golpes diciéndole que no quería salir. Este enfrentamiento duró una media hora, mientras el pastor intentaba imponerle la mano o embestirla para que cayera al suelo. Después de que el pastor la impulsó con fuerza mientras emitía oraciones, la mujer cayó al suelo y luego se levantó llorando: había vuelto a su estado normal, y el pastor declaró la liberación y pidió un aplauso para el Espíritu Santo por su papel liberador.

La duración total de este proceso puede variar de un culto a otro, pues muchas veces la gente se dispersa (algunos se desentienden de lo que está sucediendo y se devuelven a sus casas, otros se duermen en las sillas). En algunos cultos puede suceder que incluso hasta después del cierre queden personas en las que se han manifestado demonios que por su rebeldía deben ser enfrentados en lugares más privados, "para que el pastor pueda trabajar con más concentración”. La liberación se declara cuando el cuerpo se ha dejado de mover, en el caso de las manifestaciones, o cuando la víctima de una posesión pasiva abre sus ojos. No obstante, la liberación no exime a la persona de una posible posesión ulterior. 
Aunque durante las liberaciones hubo hombres que manifestaron estar poseídos, las protagonistas fueron las mujeres. Muchas de ellas expresaban la posesión por medio del llanto, y algunas mostraban explícitos sentimientos de angustia y desesperación. El pastor explicaba las causas de cada una de estas expresiones físicas y les atribuía nombres y significados distintos; así, si la persona vomitaba se trataba seguramente de "un demonio de brujería por envenenamiento". En dos ocasiones sucedió lo que el pastor llamó una "transmisión de demonio de madre a hija", cuando estas dos convulsionaron al tiempo. En uno de estos casos la hija llamaba a la madre insistentemente mientras se encontraba sumida en llanto. Posteriormente, el rumor general permitió entender que la relación entre la madre y la hija poseídas era particularmente conflictiva.

Los dos ejemplos mencionados ilustran el papel del culto como un escenario que hace explícitas situaciones que en la vida cotidiana pasan por un registro tácito. Así, la participación activa de las mujeres durante el culto, especialmente en el momento de las posesiones y las manifestaciones, les permite hacer explícitos problemas y conflictos cuyo tratamiento abierto en la vida cotidiana resultaría problemático. El momento de las liberaciones les otorga un "escudo protector" para comunicarse, pues en medio de la posesión no son ellas las que hablan, sino los demonios. Esta idea ha sido analizada por varios autores, como Scott (1990), Boddy (1989) y Lewis (1989), para el caso de los cultos de posesión ${ }^{42}$. En el culto aquí descrito los estados de trance se presentan como síntomas de conflictos o tensiones, y su manifestación corporal ofrece la posibilidad de acceder a una

42 Lewis (1989) encuentra en estos cultos una forma de protesta social de las mujeres que resultaría conflictiva si fuera expresada directamente a los hombres en otros contextos sociales; Boddy (1989) analiza un tipo de culto de posesión (zar) que llevan a cabo las mujeres en el norte de Sudán, y encuentra que mientras los hombres hallan un eje de dominación por medio del islam, las mujeres lo hacen en este culto; Scott (1990) retoma el estudio de Lewis y muestra cómo los cultos de posesión constituyen uno de los disfraces (forms of disguise) que facilitan la crítica abierta bajo otras formas de identidad (como los demonios). "liberación” pública y hacer evidentes ante toda la comunidad las tensiones y conflictos de la vida social. Esta misma función del culto se extiende a los momentos de la sanación y el testimonio. 


\section{La sanación y el testimonio: haciendo visible lo invisible y público lo privado}



urante las liberaciones el pastor concentra la atención de la gente por medio de varios recursos que hacen parte de su actuación. Por ejemplo, llama su atención para que aprendan cómo actúan los demonios en los cuerpos y cómo distinguir las diferentes manifestaciones. Esta superposición de escenas adquiere importancia en la medida en que le permite emprender una interacción con el público y, en medio de esta, provocar impresiones sobre actos inmediatos, como en el momento de la sanación. Es posible distinguir un tipo de sanación no visible, cuando el pastor llama a una persona del público que declara padecer un mal que no es evidente físicamente, por ejemplo, una migraña: el pastor le pide que describa los pormenores del mal (cuándo comenzó, la frecuencia, etc.) y posteriormente le coloca las manos sobre la cabeza para orar, y le pide cerrar los ojos. Cuando termina su oración, puede suceder que la persona caiga al suelo. En este momento, el pastor declara la sanación de esta persona y la salida del mal de su cuerpo.

Pero el pastor también puede llamar a una persona del público para "mostrar el poder de Dios" en su cuerpo. En estos casos llama a alguien que tiene un problema visible, como por ejemplo, el pie plano. En este caso, el pastor le pide a la multitud que se acerque mientras él bendice el pie del afectado al tiempo que pone sus manos sobre la extremidad. Algunas veces les pide a las personas que lo rodean que extiendan sus manos y oren por la sanación de la persona. Cuando termina su bendición, el pastor llama a la gente para que "vea el milagro” y aplauda. Aquí también podemos reconocer la efectividad de esta superposición de escenas, que entre el discurso del pastor y la inmediatez de la sanación contribuyen a la “construcción del milagro” (Ríos 2010).

Otro mecanismo puede ser la puesta en escena de un testimonio (generalmente por parte de voluntarios). Esta dimensión testimonial del culto es, como las manifestaciones que ilustramos arriba, una herramienta retórica y pública. No es solo la creación de una "realidad" por medio de la actuación del pastor, sino también una de las herramientas con las que cuenta el público para socializar un conflicto o una enfermedad y motivar reacciones (alianzas, perdón, solidaridad). 
No obstante, en El Islote esta socialización funciona de manera muy distinta que en un recinto cerrado. Pues, como lo muestra Ríos en su análisis de dos iglesias neopentecostales, la interacción entre el relator y el público durante el testimonio es tal vez el único mecanismo de información sobre "la efectividad del milagro". En ese caso, las personas no pueden "conocer la trayectoria del testimonio relatado, ni se puede llegar a saber lo que ocurrirá después a la persona que, por ejemplo, cuenta que se ha sanado y dice que no continuará con el tratamiento médico" (2010, 136). No sucede así en El Islote, donde las características espaciales someten la relación entre lo público y lo privado a una constante redefinición, pues lo que se comunica en un testimonio corresponde generalmente al terreno de una situación conocida por todos, y que no solo afecta a una persona, sino también a una familia con la que están conectadas otras.

Por ejemplo, si una persona relata públicamente un testimonio de fracaso económico, causado supuestamente por un maleficio, además de poner en conocimiento del pastor su problema puede lograr la activación de rumores, juicios, alianzas o muestras de compasión entre el público, y también hacer público al posible autor de sus males sin mencionar nombres ni establecer una confrontación directa, protegida por la atmósfera ritual y por la legitimidad de que está revestida la figura del pastor. Así mismo, el testimonio les permite a las personas ubicarse en un lugar más cercano a la religiosidad que encarna en ese momento la influencia evangélica (aunque no se definan como evangélicas necesariamente).

En este momento del culto también predominaba la toma de la palabra por parte de las mujeres. Una de ellas me expresó en momentos posteriores al culto que su participación demostraba que en la isla "las mujeres son quienes tienen la palabra". Aquí se refleja, una vez más, el papel del culto como espacio de expresión abierta del universo femenino, esta vez por medio de la dimensión testimonial.

\section{Cierre del culto: lectura y ofrenda}

ebido a la discontinuidad de la escena ritual el pastor decide
establecer el cierre, y entonces les pide a las personas que
hagan silencio y concentren su atención en él, pues va a leer
un pasaje de la Biblia. En este momento el pastor se expresa 
con un tono paternalista, por ejemplo: "Ahora siéntense todos, cierren sus ojitos, vamos a escuchar la palabra de Dios". Así, el pastor se asegura de convertir su figura de autoridad en una más protectora y familiar, y la atmósfera ritual se hace menos tensa. También puede haber interacciones en las cuales el pastor llama a las personas a leer pasajes de la Biblia o a representar parábolas que resultan divertidas para las personas.

Luego, el pastor introduce poco a poco un discurso sobre su condición de pastor itinerante, que no necesita grandes sumas de dinero para viajar pues por ser un enviado de Dios las personas le aseguran la comida y la estadía. Así que poco a poco llama la atención sobre el papel de la ofrenda en la vida de un predicador como él. Les pide a los presentes que hagan una fila, y mientras las personas avanzan van depositando una pequeña cantidad de dinero en una canasta que puede ser sostenida por el pastor, por el profeta o por alguno de sus ayudantes. El pastor agradece y luego declara el cierre del culto e invita a los asistentes a volver a sus casas.

Después de este cierre, las funciones del culto como espacio de lo explícito fueron reemplazadas por la recomposición casi inmediata de las relaciones habituales. Después de las acusaciones indirectas de brujería, los testimonios y las sanaciones, se esperarían reacciones de alianzas, compasión, curiosidad o rechazo directos por parte de las personas; pero, en este microescenario de la vida social que es El Islote, era sorprendente ver la facilidad con que las personas pasaban de un registro de comunicación abierto y directo como el culto al terreno cotidiano del rumor y el humor, sin que resultaran afectadas de forma dramática las condiciones habituales de las interacciones cotidianas.

\section{Conclusión}

\ n isleño que actualmente participa del Movimiento Misionero Mundial afirmó en un reportaje reciente sobre El Islote (Mojica 2012) que un gran número de habitantes se ha vuelto evangélico porque "los curas solo van una vez al año a bautizar a los niños". Esta afirmación ilustra dos aspectos: el primero, del cual se quiso dar cuenta en este artículo, es la capacidad de adaptación de la influencia evangélica, gracias a la presencia de una religiosidad discontinua y fluctuante que tiene como escenario 
el itinerario de los pastores y que no necesita de la permanencia religiosa ni de la existencia formal de un templo. En segundo lugar, la afirmación ilustra la variabilidad local de los procesos de conversión (Vilaça 2002) pues, como se intuye en el argumento, la conversión no está basada en un rechazo de una doctrina sino en que los pastores hacen más presencia que los curas católicos. En este caso, la influencia de los pastores no conllevó la creación de una comunidad evangélica, sino la existencia de una ambigüedad entre la presencia católica y la evangélica. Una de las razones de esta ambigüedad se halla en los alcances y límites de la acción ritual evangélica, que, aunque presenta características como la inmediatez de la acción ritual y la puesta en marcha de dispositivos de participación pública, tiene sus límites en referencias católicas como el culto a los muertos ${ }^{43} \mathrm{o}$ a los santos, que no encuentran asidero en la doctrina evangélica.

Por esta razón, como lo afirma Vilaça (2002), el fenómeno religioso debe considerarse como un sistema, es decir, en su relación con las características sociales y cosmológicas que lo rodean. En

43 Que en El Islote, al igual que en otras poblaciones negras del país, se realiza por medio del novenario católico y de la socialización intensa del dolor, como sucede con la expresión abierta del llanto, de manera similar a los hábitos funerarios de las poblaciones negras que describe Escalante (1964). el caso de El Islote, la presencia evangélica está ligada a lo reducido de su espacio, a la fluctuación constante de la presencia religiosa y a la circulación de su población entre las islas y el continente. No obstante, este tipo de aproximación no se restringe a la descripción de lugares lejanos y de difícil acceso, sino que puede ser útil y enriquecedora para explorar también las religiosidades urbanas - por ejemplo, en los barrios- en las que se advierten formas disímiles de la presencia religiosa. Esta mirada nos permitiría explorar las rutas, redes y recomposiciones locales, en manos de figuras como los pastores que describimos aquí, quienes constituyen motores anónimos, pero poderosos, de la expansión evangélica.

\section{Agradecimientos}

Agradezco a la profesora Anne-Marie Losonczy por sus indicaciones y revisiones de mi trabajo etnográfico sobre este tema, realizado durante los años 2010 y 2011, como parte de la investigación para 
mi tesis doctoral en curso. También a los evaluadores anónimos de la Revista Colombiana de Antropología que formularon sugerencias tras leer la primera versión de este texto.

\section{ReFERENCIAS}

Alonso, Oriana. 2010. "Una gran familia: humor e identidad en El Islote de San Bernardo, Cartagena, Bolívar”. Tesis de pregrado, Facultad de Ciencias Sociales y Humanas, Universidad Externado de Colombia, Bogotá.

Bastide, Roger. 1972. Le rêve, la transe et la folie. París: Flammarion.

Baubérot, Jean y Jean Paul Willaime. 1990. abC du protestantisme: motsclés, lieux, noms. Ginebra: Labor et Fides.

Boddy, JANnice. 1989. Wombs and Alien Spirits: Women, Men and the Zar Cult in Northern Sudan. Madison: University of Wisconsin Press.

Bourguignon, Erika. 1976. Possession. San Francisco: Chandler and Sharp.

BOYER, VÉroniQue. 2008. Expansion évangélique et migrations en Amazonie brésilienne, la renaissance des perdants. París: IRD y Karthala.

Brusco, Elizabeth. 1986. "The Household Basis of Evangelical Religion and the Reformation of Machismo in Colombia". Tesis de doctorado, University of New York.

Brusco, Elizabeth. 1995. The Reformation of Machismo. Evangelical Conversion and Gender in Colombia. Austin: University of Texas Press.

Cox, Harvey. 1995. Fire of Heaven: The Rise of Pentecostal Spirituality and the Reshaping of Religion in the Twenty-first Century. Massachusetts: Da Capo Press.

De Certeau, Michel. 1970. La possession de Loudun. París: Julliard.

De Heusch, Luc. 2006. La transe et ses entours: la sorcellerie, l'amour fou, saint Jean de la Croix, etc. Bruselas: Complexe.

DubleumorTier, Nathalie. 1997. Glossolalie. Discours de la croyance dans un culte pentecôtiste. París: L’Harmattan.

Durán, CARLos. 2007. ¿Es nuestra isla para dos?: conflictos por el desarrollo y la conservación en las islas del Rosario, Cartagena. Bogotá: Universidad de los Andes.

Escalante, Aquiles. 1964. El negro en Colombia. Bogotá: Universidad Nacional de Colombia. 
Flora, Cornelia Butler. 1970. Pentecostalism in Colombia, Baptism by Fire and Spirit. Londres: Associated University Press.

Flora, Cornelia Butler. 1975. "Pentecostal Women in Colombia. Religious Change and the Status of Working-Class Women”. Journal of Interamerican Studies and World Affairs 17 (4): 411-425.

Garma Navarro, Carlos. 2004. Buscando el espíritu. Pentecostalismo en Iztapalapa y Ciudad de México. Iztapalapa: Universidad Autónoma Metropolitana.

Goffman, ERving. 1973. La mise en scéne de la vie quotidienne: la presentation de soi. París: Minuit.

LeIRIs, Michel. 1958. La possession et ses aspects théâtraux chez les Ethiopiens de Gondar. París: Plon.

Lewis, IoAn Myrddin. 1989. Ecstatic Religion. A Study of Shamanism and Spirit Possession, 2. ${ }^{\mathrm{a}}$ ed. Nueva York: Routledge.

Losonczy, AnNe MARIE. 2007. La trama interétnica. Ritual, sociedad y figuras de intercambio entre los grupos negros y emberá del Chocó. Bogotá: Instituto Colombiano de Antropología e Historia.

Mojica Patiño, José Alberto. 2012. "El Islote: el pueblo donde viven apretadas 1.000 personas en 98 casas”. El Tiempo, 18 de enero, http:// www.eltiempo.com/colombia/cartagena/ARTICULO-WEB-NEW_NOTA_INTERIOR-10964801.html

Pereira Souza, Ana Mercedes. 1996. "El pentecostalismo: nuevas formas de organización religiosa en los sectores populares. Origen, evolución y funciones en la sociedad colombiana, 1960-1995”. Historia Crítica 12: 43-68.

Pereira Souza , Ana Mercedes. 1998. "La pluralidad religiosa en Colombia. Iglesias y sectas”. En Nueva historia de Colombia, vol. 9. Bogotá: Planeta.

RAVAGLI, JoRgE. 2010. “Música, fervor y construcción de identidad. Evolución de la expresión musical en la Iglesia Pentecostal Unida de Colombia”. En El pentecostalismo en Colombia: prácticas religiosas, liderazgo y participación política, editado por Clemencia Tejeiro Sarmiento, 155-182. Bogotá: Universidad Nacional de Colombia.

Reyes, Gina Marcela. 2010. "El don de la profecía en la Iglesia de Dios Ministerial de Jesucristo Internacional”. En El Pentecostalismo en Colombia: prácticas religiosas, liderazgo y participación política, editado por Clemencia Tejeiro Sarmiento, 183-212. Bogotá: Universidad Nacional de Colombia.

Ríos, ANDRÉs. 2002. Identidad y religión en la colonización del Urabá antioqueño. Bogotá: Ascun. 
Ríos, SANDRA. 2010. "La construcción retórica del milagro. Análisis del discurso religioso pentecostal”. En El pentecostalismo en Colombia: prácticas religiosas, liderazgo y participación política, editado por Clemencia Tejeiro Sarmiento, 117-154. Bogotá: Universidad Nacional de Colombia.

Rondón Palmera, CÉSAR. 2007. "Pentecostalismo y minorías religiosas. Aportes a la sociología de la religión”. Revista Colombiana de Sociología 28: 95-113.

Rouget, Gilbert. 1990. La musique et la transe. París: Gallimard.

SAlas, YolandA. 1998. "Cultura, retórica y poder del pentecostalismo evangélico: Iglesia Dios es Amor”. En El pentecostalismo en América Latina: entre tradición y globalización, coordinado por Angelina Pollak- Eltz y Yolanda Salas, 19-38. Quito: Abya-Yala.

SÁNCHEZ, IvONNE. 2005. “Id y haced discípulos a todas las naciones'. Estrategias de trabajo, evangelización, crecimiento y aceptación del protestantismo: explorando el caso de las iglesias protestantes de Quibdó”. Tesis de maestría, Departamento de Antropología, Universidad de los Andes, Bogotá.

Scott, James. 1990. Domination and the Arts of Resistance. Hidden Transcripts. Londres: Yale University Press.

Tejeiros, Clemencia, ed. 2010. El pentecostalismo en Colombia. Prácticas religiosas, liderazgo y participación política. Bogotá: Universidad Nacional de Colombia.

VILAÇA, ApARECIDA. 2002. "Missions et conversions chez les Wari', entre protestantisme et catholicisme”. L'Homme 164: 57-80.

Wilson, Peter J. 2004. Las travesuras del cangrejo: un estudio de caso caribe del conflicto entre reputación y respetabilidad. San Andrés Isla: Universidad Nacional de Colombia.

Willaime, Jean Paul. 1986. Profession, pasteur: sociologie de la condition du clerc à la fin du xxe siècle. Ginebra: Labour et Fides. 